\title{
BUCKLING OF MULTILAYERED LAMINATED GLASS BEAMS: VALIDATION OF THE EFFECTIVE THICKNESS CONCEPT
}

F. Pelayo ${ }^{a^{*},}$ M López-Aenlle ${ }^{\mathrm{a}}$, G. Ismael ${ }^{\mathrm{a}}$, A. Fernández-Canteli ${ }^{\mathrm{a}}$.

aDepartment of Construction and Manufacturing Engineering, University of Oviedo, Campus de Gijón, Zona Oeste, Edificio 7, 33203, Gijón, Spain.

*corresponding author; E-mail: fernandezpelayo@uniovi.es

Phone: +34985 182057, Fax: +34985182433

\begin{abstract}
Stability of laminated structural glass is one of the design requirements to be considered due to the brittle and slender nature of this kind of glass elements. Since laminated glass is mainly manufacture with viscoelastic interlayers, its mechanical properties are temperature and time dependent. This implies that, i.e., the critical load of a laminated glass beam subject to constant compressive load decreases with time as well as with temperature.
\end{abstract}

In this paper, the equations of the Euler Theory for buckling of monolithic beams are extended to multi-layered laminated glass beams using an effective stiffness. This proposal is based on the idea of calculating the thickness (time and temperature dependent) of a monolithic element with bending properties equivalent to those of the laminated one, that is, the deflections provided by the equivalent monolithic beam are equal to those of the layered model with viscoelastic core.

In this work, the analytical predictions are validated by compressive experimental tests carried out on a simply supported beam composed of three glass layers and two polyvinyl butiral (PVB) interlayers. Moreover, a finite element model was assembled to validate the proposed methodology for any boundary conditions. The results shown that a good accuracy can be obtained with the proposed equations being the errors less than $7 \%$ for all the experiments and simulations considered. 


\section{KEYWORDS}

Laminated glass, structural composites, PVB, bucking, structural stability, viscoelasticity. 
NOMENCLATURE

$A_{1}=b H_{1} \quad$ Area of glass layer 1 in laminated glass

$A_{2}=b H_{2} \quad$ Area of glass layer 2 in laminated glass

$A_{3}=b H_{3} \quad$ Area of glass layer 3 in laminated glass

E $\quad$ Glass Young modulus of glass layers

$E_{t}(t) \quad$ Viscoelastic relaxation tensile modulus for polymeric interlayer

$G_{t}(t) \quad$ Viscoelastic relaxation shear modulus for the polymeric interlayer

$H_{1} \quad$ Thickness of glass layer 1 in laminated glass

$H_{2} \quad$ Thickness of glass layer 2 in laminated glass

$H_{3} \quad$ Thickness of glass layer 3 in laminated glass

$H_{T O T}=H_{1}+H_{2}+H_{3}$

$H_{12}=t_{1}+\left(\frac{H_{1}+H_{2}}{2}\right)$

$H_{23}=t_{2}+\left(\frac{H_{2}+H_{3}}{2}\right)$

I Second moment of area

$I_{1}=b \frac{H_{1}^{3}}{12}$

$I_{2}=b \frac{H_{2}^{3}}{12}$

$I_{3}=b \frac{H_{3}^{3}}{12}$ 


$$
\begin{aligned}
& I_{T 2}=I_{1}+I_{2}=b \frac{H_{1}^{3}+H_{2}^{3}}{12} \\
& I_{T 3}=I_{1}+I_{2}+I_{3}=b \frac{H_{1}^{3}+H_{2}^{3}+H_{3}^{3}}{12} \\
& I_{T N}=N b \frac{H^{3}}{12} \\
& K_{2}(t, T) \quad \text { Viscoelastic bulk modulus } \\
& \mathrm{L} \quad \text { Length of a glass beam } \\
& \mathrm{T} \quad \text { Reference temperature } \\
& T_{0} \quad \text { Temperature }
\end{aligned}
$$

\section{LOWERCASE LETTERS}

$\begin{array}{ll}a_{T} & \text { Shift factor } \\ b & \text { Width of a glass beam } \\ t & \text { Time } \\ t_{1} & \text { Thickness of polymeric layer } 1 \text { in laminated glass } \\ t_{2} & \text { Thickness of polymeric layer } 2 \text { in laminated glass }\end{array}$

\section{GREEK LETTERS}

$\eta_{2} \quad$ Loss factor of the polymeric interlayer of laminated glass

$v \quad$ Poisson ratio of the glass layers

$v_{2}(t, T) \quad$ Viscoelastic Poisson ratio of the polymeric interlayer 


\section{INTRODUCTION}

Laminated glass is a sandwich or layered material which consists of two or more plies of monolithic glass, whose mechanical behaviour is commonly assumed linear elastic, and one or more interlayers of a polymeric material which show a viscoelastic behaviour i.e. their mechanical properties are time (or frequency) and temperature dependent $[1,2]$.

Multi-layered laminated glass panels can be used for many different applications due to the added thickness and strength. They are commonly used in accessible glazing, i.e. floors, roofs and other horizontal glazing accessible to the public or at least for cleaning and maintenance [3]. In these applications, resistance against impact caused by a hard or soft body, the post-breakage behavior as well as the slip resistance must be examined [3]. Multilayered glass beams are also interested in acoustics and structural dynamics in order to reduce the acoustic transmission and amplitude of vibrations.

If laminated glass elements are subject to compressive loads, the structural stability is one of the design requirements because laminated glass elements are brittle and slender. Due to the fact that the stiffness of the interlayer is temperature and time dependent, the same can be said about the critical load, i.e., the critical load of a laminated glass beam subject to constant compressive load decreases with time.

The concept of effective thickness has been proposed in recent years $[4,5,6]$ based on the quasi-elastic solution. This method consists of calculating the thickness (time and temperature dependent) of a monolithic element with bending properties equivalent to those of the laminated one, that is to say, the deflections provided by the equivalent monolithic beam are equal to those of the layered model with viscoelastic core. The concepts of effective Young modulus and effective stiffness [7] can be used interchangeably with the same accuracy.

Several analytical models have been proposed for determining the critical load of a simply supported laminated glass beam [8, 9, 10, 11]. Aenlle et al. [12] extended the Euler Theory to laminated glass beams using an effective stiffness (or effective thickness) and the effect of the boundary conditions is considered through the buckling ratio $\beta$. 
In this paper, equations for predicting the critical load of multi-layered glass beams with different boundary conditions are proposed based on the methodology proposed by Aenlle et al. [12] which uses the Euler theory [13] of monolithic beams, the quasielastic solution [6] and the effective stiffness concept [7]. In order to validate the model, the critical load of a laminated glass beams, made of three annealed glass plies and two PVB interlayers, were predicted using the effective stiffness concept and validated by experimental tests and numerical models. Moreover, the effect of the number of layers in the critical load of multi-layered glass beams are investigated and some recommendations are proposed for the design of these elements subject to compressive loadings.

\section{THEORY}

The critical load of a simply supported linear-elastic monolithic beam, according to the Euler theory is given by $[13,14]$

$P_{\text {crit }}=\frac{\pi^{2} E I}{L^{2}}$

Eq. (1) can be extended to laminated glass beams $[8,9,10]$ using an effective $E \mathrm{I}(\mathrm{t}, \mathrm{T})_{\text {eff }}$ , i.e.:

$P_{\text {crit }}(\mathrm{t}, \mathrm{T})=\frac{\pi^{2} \mathrm{EI}(\mathrm{t}, \mathrm{T})_{\mathrm{eff}}}{L^{2}}$

In the case of a simply supported laminated glass beam composed of 2 glass layers and one linear-viscoelastic interlayer (see Figure 1) the following expression for $I(t, T)_{e f f}$ :

$\mathrm{EI}(\mathrm{t}, \mathrm{T})_{\mathrm{eff}}=E I_{T 2}\left(1+\frac{Y_{B 2}}{1+\frac{E H_{1} H_{2} t_{1}}{G_{t}(t, T)\left(H_{1}+H_{2}\right)} \frac{\pi^{2}}{L^{2}}}\right)$

can be derived from the models proposed in $[8,9,10]$, where 
$Y_{B 2}=\frac{b H_{12}^{2} H_{1} H_{2}}{I_{T 2}\left(H_{1}+H_{2}\right)}$

The critical load of an elastic monolithic beam with different boundary conditions can also be calculated with Eq. (1) but using the buckling ratio $\beta$ i.e.:

$P_{\text {crit }}=\frac{\pi^{2} E I}{(\beta L)^{2}}$

Aenlle and Pelayo [12] proposed to extend Eq. (5) for laminated glass beams using the equation:

$P_{c r i t}(t, T)=\frac{\pi^{2} \mathrm{EI}(\mathrm{t}, \mathrm{T})_{\mathrm{eff}}}{(\beta L)^{2}}$

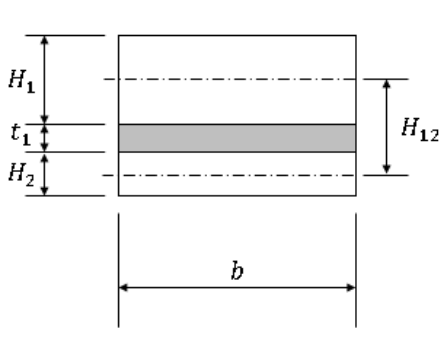

a)

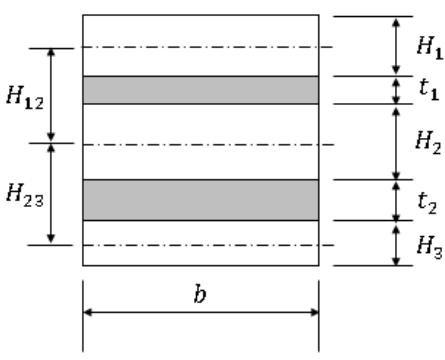

b)

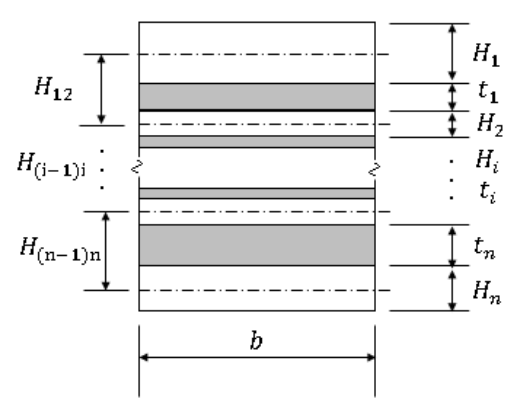

c)

Figure 1. Section of laminated glass beams (a) 2 glass layers (b) 3 glass layers and (c) $\mathrm{N}$ glass layers of equal thickness.

Where $\mathrm{EI}(\mathrm{t}, \mathrm{T})_{\text {eff }}$ is an effective stiffness. In the case of a laminated glass beams with 2 glass layers and one linear-viscoelastic interlayer (fig. 1) Aenlle and Pelayo [12] derived an expression for EI $(\mathrm{t}, \mathrm{T})$ eff from the model of Galuppi and Royer Carfagni [6] which is given by: 
$\mathrm{EI}(\mathrm{t}, \mathrm{T})_{\mathrm{eff}}=\mathrm{EI}_{\mathrm{T} 2}\left(1+\frac{Y_{B 2}}{1+\frac{E H_{1} H_{2} t_{1}}{\mathrm{bG}_{\mathrm{t}}(t, T)\left(H_{1}+H_{2}\right)} \psi_{B}}\right)$

Where [12]:

$\psi_{B}=\frac{\pi^{2}}{(\beta L)^{2}}$

In Eqs. (7) and (8) the buckling ratio $\beta$ coincide with those of a monolithic beam with the same boundary conditions.

In this paper, an expression for the effective stiffness $\mathrm{EI}(\mathrm{t}, \mathrm{T})_{\mathrm{eff}}$ of laminated glass beams composed of three glass layers of thicknesses $\mathrm{H}_{1} \mathrm{H}_{2}$ and $\mathrm{H}_{3}$ and 2 polymeric interlayers with thickness $t_{1}$ and $t_{2}$ (fig. 1) was derived from the Galuppi and Royer Carfagni model [15] which is expressed as :

$\mathrm{EI}(\mathrm{t}, \mathrm{T})_{\mathrm{eff}}=\mathrm{EI}_{\mathrm{T} 3}\left(1+\frac{Y_{B 3}}{1+\frac{E I_{T 3} \mathrm{Y}_{\mathrm{B} 3}}{b G_{t}(\omega, T)\left(\frac{H_{12}^{2}}{t_{1}}+\frac{H_{23}^{2}}{t_{2}}\right)} \psi_{B}}\right)$

Where $\psi_{B}$ is given by Eq. (8) and

$Y_{B 3}=\frac{\left(A_{1} d_{1}^{2}+A_{2} d_{2}^{2}+A_{3} d_{3}^{2}\right)}{\mathrm{I}_{\mathrm{T} 3}}$

being:

$$
\begin{aligned}
& d_{1}=\frac{H_{2} H_{12}+H_{3}\left(H_{12}+H_{23}\right)}{H_{1}+H_{2}+H_{3}} \\
& d_{2}=-\frac{H_{1} H_{12}-H_{3} H_{23}}{H_{1}+H_{2}+H_{3}}
\end{aligned}
$$




$$
d_{3}=-\frac{H_{2} H_{12}+H_{3}\left(H_{12}+H_{23}\right)}{H_{1}+H_{2}+H_{3}}
$$

The concept of dynamic effective Young modulus is defined as the Young modulus of a monolithic glass beam with constant thickness, which provides the same stiffness as the beam at hand. This technique is more attractive when finite element models are used to calculate laminated glass beams because a monolithic model with constant thickness is assembled whereas the Young modulus is defined as time and temperature dependent [7]. If the monolithic model has inertia $I_{M O N}$ from Eq. (9) the following expression for the effective Young modulus is derived:

$$
E_{e f f}(t, T)=E \frac{I_{T 3}}{I_{M O N}}\left(1+\frac{Y_{B 3}}{1+\frac{E I_{T 3} Y_{\mathrm{B} 3}}{b G_{t}(\omega, T)\left(\frac{H_{12}^{2}}{t_{1}}+\frac{H_{23}^{2}}{t_{2}}\right)} \psi_{B}}\right)
$$

Using Eq. (12) the critical load is calculated by means of the equation:

$P_{c r i t}(t, T)=\frac{\pi^{2} E_{e f f}(t, T) I_{M O N}}{(\beta L)^{2}}$

In the case of a laminated glass beam composed of $\mathrm{N}$ glass layers (multilayered, see Figure 1) with thickness $\mathrm{H}$ and N-1 polymeric interlayers with thickness $t$, the effective stiffness is given by [15]:

$$
\mathrm{EI}(\mathrm{t}, \mathrm{T})_{\mathrm{eff}}=\mathrm{EI}_{\mathrm{TN}}\left(1+\frac{Y_{B N}}{1+\frac{E N(N+1) H t}{12 \mathrm{G}_{\mathrm{t}}(t, T)} \psi_{B}}\right)
$$

where:

$$
Y_{B N}=\frac{(t+H)^{2}(N-1)(N+1)}{H^{2}}
$$


The effective Young modulus is given by:

$$
E_{e f f}(t, T)=E \frac{I_{T N}}{I_{M O N}}\left(1+\frac{Y_{B N}}{1+\frac{E N(N+1) H t}{12 \mathrm{G}_{\mathrm{t}}(t, T)} \psi_{B}}\right)
$$

\section{BUCKLING DESIGN OF MULTILAYERED GLASS BEAMS}

Norville [16] and Galuppi and Royer-Carfagni [5, 6] pointed out that the response of laminated glass beams presents two borderlines: 1) The layered limit corresponding to the case when the beam consists of free-sliding glass plies and 2) the monolithic limit, when the Euler-Bernoulli assumptions hold for the entire section of the laminate glass element. Hereafter we will denote the monolithic critical load as $\mathrm{P}_{\text {crit }}^{0}$ and the layered limit as $\mathrm{P}_{\text {crit }}^{\infty}$.

When PVB is used as interlayer, the shear modulus of the interlayer $\mathrm{G}_{\mathrm{t}}(t, T)$ can take small values but no zero and the layered limit is never reached. Thus a new limit $\mathrm{P}_{\text {crit }}^{\mathrm{min}}$, associated with the minimum value of $G_{t}(t, T)$, must also be considered. We can be very close to the layered limit with short beams, boundary conditions related to high values of $\psi_{B}$ and low values of $\mathrm{G}_{\mathrm{t}}(t, T)$, i.e., at long term.

With respect to the monolithic limit, it is reached when the $G_{t}(t, T)$ tends to infinity. Again, this limit is never reached but due to the relative high magnitude of $\mathrm{G}_{\mathrm{t}}(t, T)$ at short term, the monolithic limit is always very close to maximum critical load $\mathrm{P}_{\text {crit }}^{\max }$ associated to maximum of $\mathrm{G}_{\mathrm{t}}(t, T)$.

In figure 2, it is shown the critical load of a laminated glass beam with $H_{1}=H_{2}=$ $6 \mathrm{~mm}$ and one PVB interlayer with thickness $t_{1}=0.76 \mathrm{~mm}$ at different temperatures which were predicted with Eq. (6). It can be observed that the critical load decreases rapidly with time mainly at temperatures over $20^{\circ} \mathrm{C}$. For a laminated glass beam permanently compressed, the load acting on the beam must be less than $\mathrm{P}_{\text {crit }}^{\min }$. Buckling loads over $\mathrm{P}_{\text {crit }}^{\min }$ could only be considered when the compressive load acts on the beam for a short period of time. Thus, in practical applications the compressive load a must be less than $\mathrm{P}_{\text {crit }}^{\min }$ in order to prevent buckling failures. To consider the layered limit $\mathrm{P}_{\text {crit }}^{\infty}$ 
will be obviously conservative. On the other hand, the critical loading of a laminated glass beam is always less than the critical loading of monolithic beam with the same total thickness.

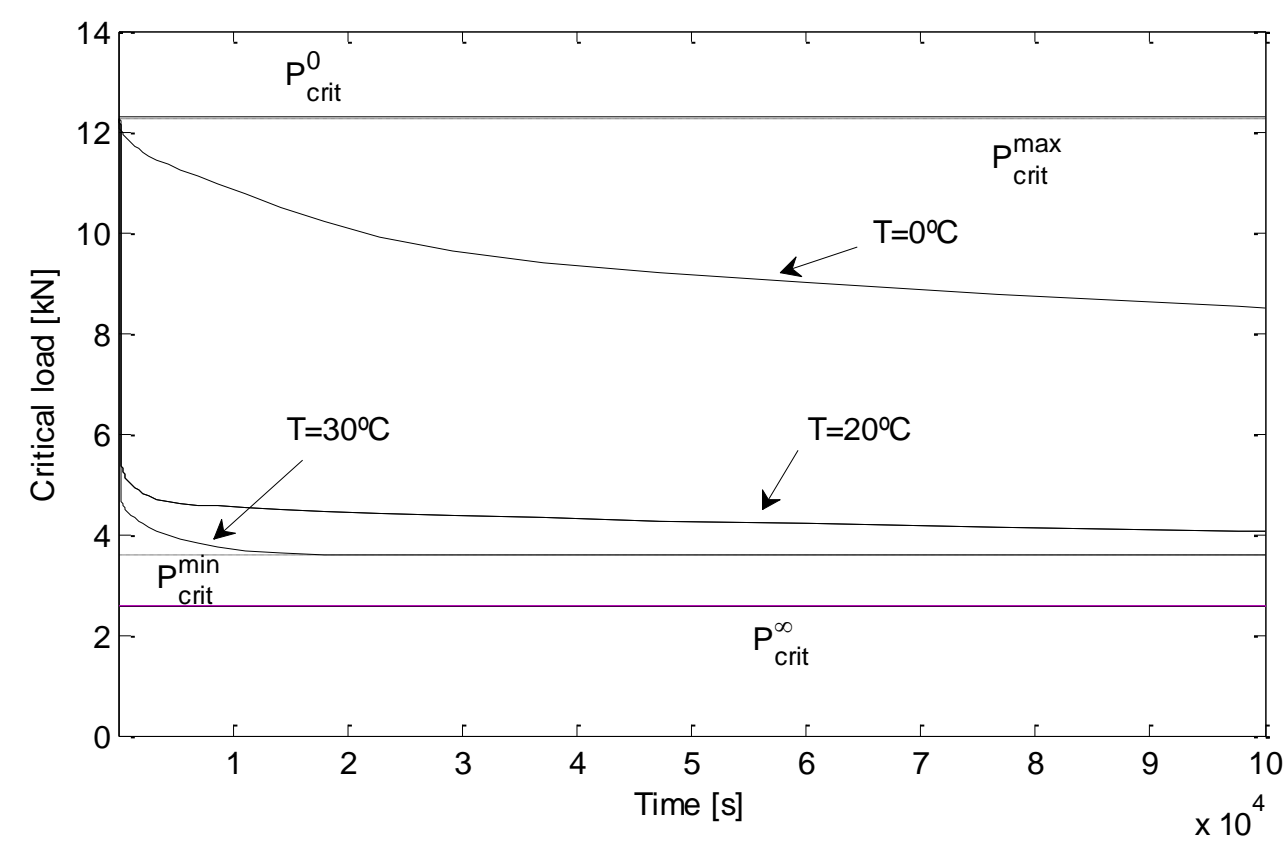

Figure 2. Critical load of a simple supported laminated glass beam at different temperatures.

The ratio $\frac{\mathrm{P}_{\text {crit }}^{0}}{\mathrm{P}_{\text {crit }}^{\infty}}$ depends on the geometry of the beam. Parameters $Y_{B 2}, Y_{B 3}$ and $Y_{B N}$ are constant coefficients that relates the monolithic and the layered limits of the effective stiffness $E I(t, T)_{\text {eff }}$ by means of the expression

$$
1+Y=\frac{\text { monolithic limit of } E I(t, T)_{\text {eff }}}{\text { layered limit of } E I(t, T)_{\text {eff }}}=\frac{E I(0, T)_{\text {eff }}}{E I(\infty, T)_{\text {eff }}}=\frac{\mathrm{P}_{\mathrm{crit}}^{0}}{\mathrm{P}_{\mathrm{crit}}^{\infty}}
$$

In order to study the effect of the number of layers, we are going to consider a multilayered glass beam with $N$ glass layers of equal thickness $\mathrm{H}$ and $N-1$ interlayers of equal thickness t. In this particular case, Eq. (17) is given by:

$1+Y=N^{2}\left(1+\left(\frac{N-1}{N}\right) \frac{t}{H}\right)^{3}$

Combining Eqs. (17) and (18) it is inferred that: 
$\frac{\mathrm{P}_{\text {crit }}^{0}}{\mathrm{P}_{\text {crit }}^{\infty}}=N^{2}\left(1+\left(\frac{N-1}{N}\right) \frac{t}{H}\right)^{3}$

Two laminated beams with the same total thickness but different number of layers show the same monolithic limit $\mathrm{P}_{\text {crit }}^{0}$ but From Eq. (19) it is easily inferred that the layered limit $\mathrm{P}_{\text {crit }}^{\infty}$ diminishes with increasing number of layers. Thus, in the design of laminated glass beams subject to buckling we must try to maximize the layered limit $\mathrm{P}_{\text {crit }}^{\infty}$ which means that the number of layers must be minimized. This effect is shown in figure 3 where it is presented the critical load of a simply supported laminated glass beam $1 \mathrm{~m}$ long and $0.1 \mathrm{~m}$ wide and composed of two glass layers with thickness $H_{1}=H_{2}=$ $6 \mathrm{~mm}$ and one PVB interlayer with thickness $t_{1}=0.76 \mathrm{~mm}$. The critical load of a laminated glass beam with the same geometry but composed of three glass layers with thicknesses $H_{1}=H_{2}=H_{3}=4 \mathrm{~mm}$ and two PVB interlayers with thicknesses $t_{1}=$ $t_{2}=0.76 \mathrm{~mm}$ is also shown in the same figure for comparison. Both beams have the same total thickness and consequently the same monolithic limit $\mathrm{P}_{\text {crit }}^{0}$, but the beam with two glass layers present the highest layered limit $\mathrm{P}_{\text {crit }}^{\infty}$ being 2.25 times larger than that of the beam with three glass layers. Moreover, $\mathrm{P}_{\text {crit }}^{\min }$ of the beam with two layers is 1.28 times largest than that corresponding to the beam with three layers.

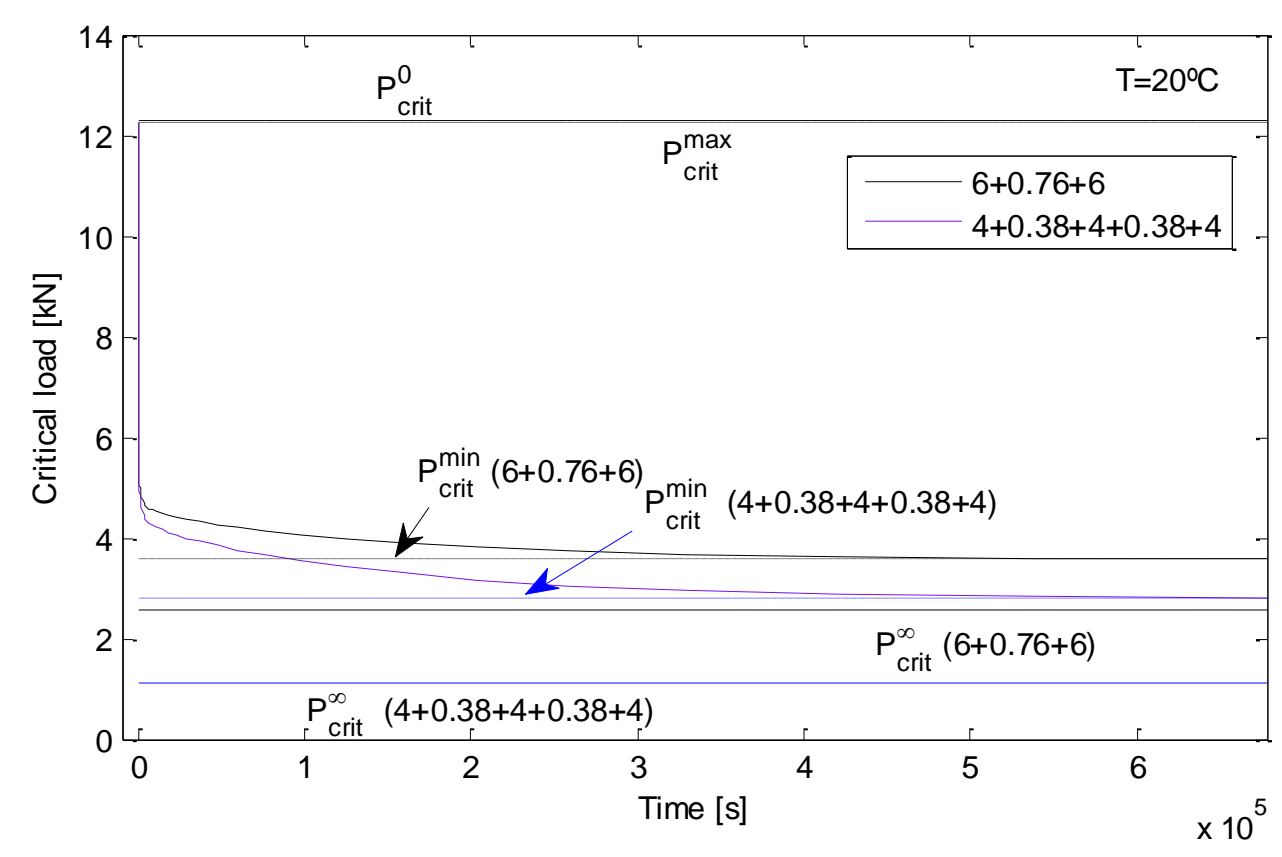


Figure 3. Comparison of the critical load for same total thickness between 3 layered and 2 layered (sandwich) laminated glass beams.

With respect to the limit $\mathrm{P}_{\text {crit }}^{\min }$, it depends on $\mathrm{G}_{\mathrm{t}}(\infty, T)$ and on the geometry of the beam (thicknesses, length and boundary conditions). In figure 4, it is presented the parameter $\gamma_{\min }$ which relates the minimum critical load a beam with two glass layers with that of a beam with $\mathrm{N}$ layers, both beams having the same total thickness $H_{T O T}$, i.e. :

$\gamma_{\min }=\frac{\mathrm{P}_{\text {crit }}^{\min }(N \text { glass layers })}{\mathrm{P}_{\text {crit }}^{\min }(2 \text { glass layers })}$

The curves in figure 4 corresponds to a simply supported beam $1 \mathrm{~m}$ long and $0.10 \mathrm{~m}$ wide. Three different glass thicknesses $\left(H_{1}=H_{2}=4,6\right.$ and $\left.8 \mathrm{~mm}\right)$ have been considered for the reference beam (two glass layers and one PVB interlayer) whereas the thickness of the PVB interlayer has always been $t_{1}=0.76 \mathrm{~mm}$.

From the figure 4 is inferred that $\gamma_{\min }$ is always less than 1 which means that the beam with two glass layers always presents the highest value $\mathrm{P}_{\text {crit }}^{\min }$. However $\gamma_{\min }$ increases as the total thickness $H_{T O T}$ decreases. 


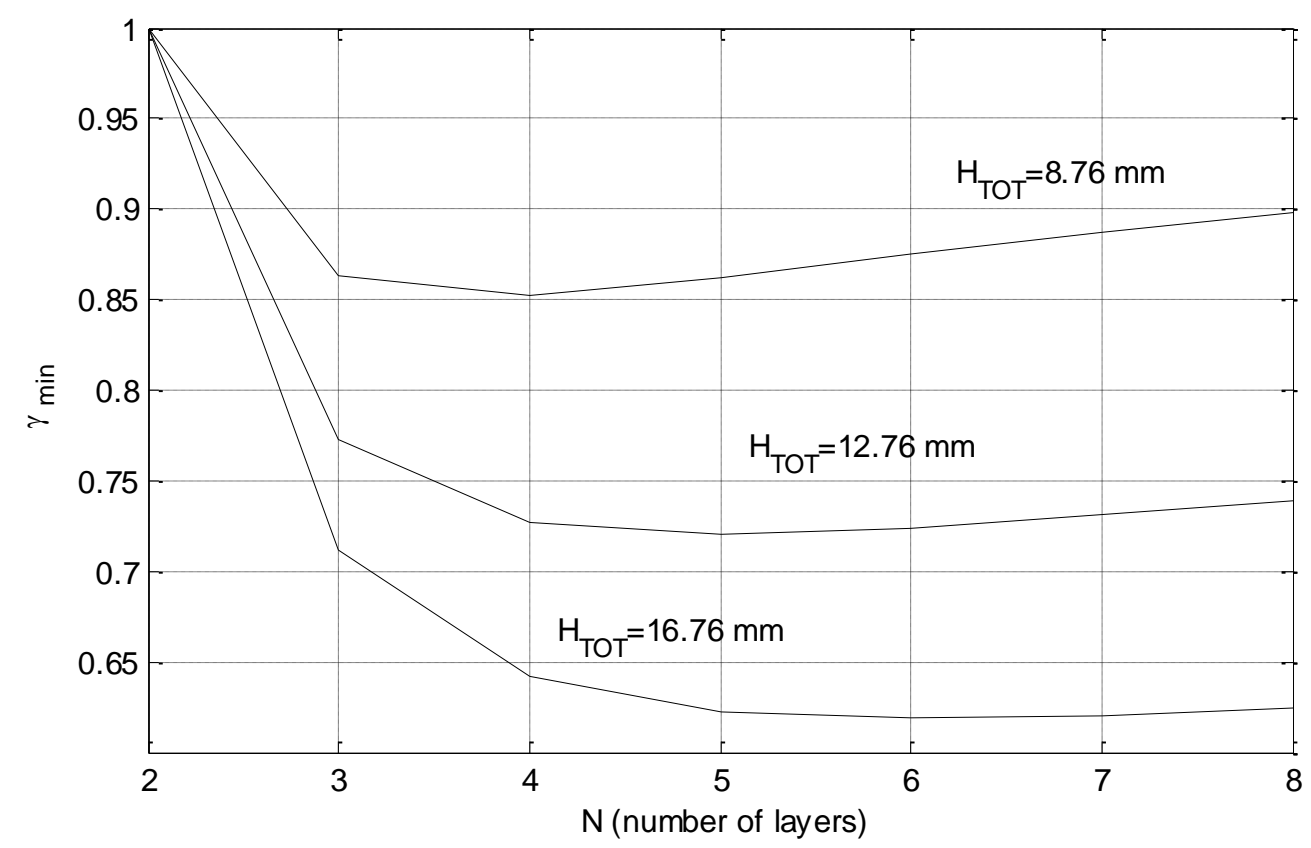

Figure 4. Influence of the number of layers on the minimum critical load $\mathrm{P}_{\text {crit }}^{\min }$.

\section{EXPERIMENTAL AND NUMERICAL VALIDATION}

\subsection{Experimental program}

A simply supported beam with the following geometrical data: $H_{1}=H_{2}=H_{3}=4 \mathrm{~mm}$, $t_{1}=t_{2}=0.76 \mathrm{~mm}, L=0.7 \mathrm{~m}$ and $b=0.1 \mathrm{~m}$ was tested at temperature $T=25^{\circ} \mathrm{C}$ in a standard axial machine MTS810 - 250kN (see figure 5). Three tests were carried out where the axial displacement of the beam was increased with a constant rate of: 0.1 $\mathrm{mm} / \mathrm{min}, 0.2 \mathrm{~mm} / \mathrm{min}$ and $1 \mathrm{~mm} / \mathrm{min}$, respectively. The relation between the axial force recorded by the machine and the bending deflection at the mid-span measured with a laser sensor is presented in figure 6 for the three cases. The tests were stopped when the bending deflection reached a magnitude of approximately $4-7 \mathrm{~mm}$. 

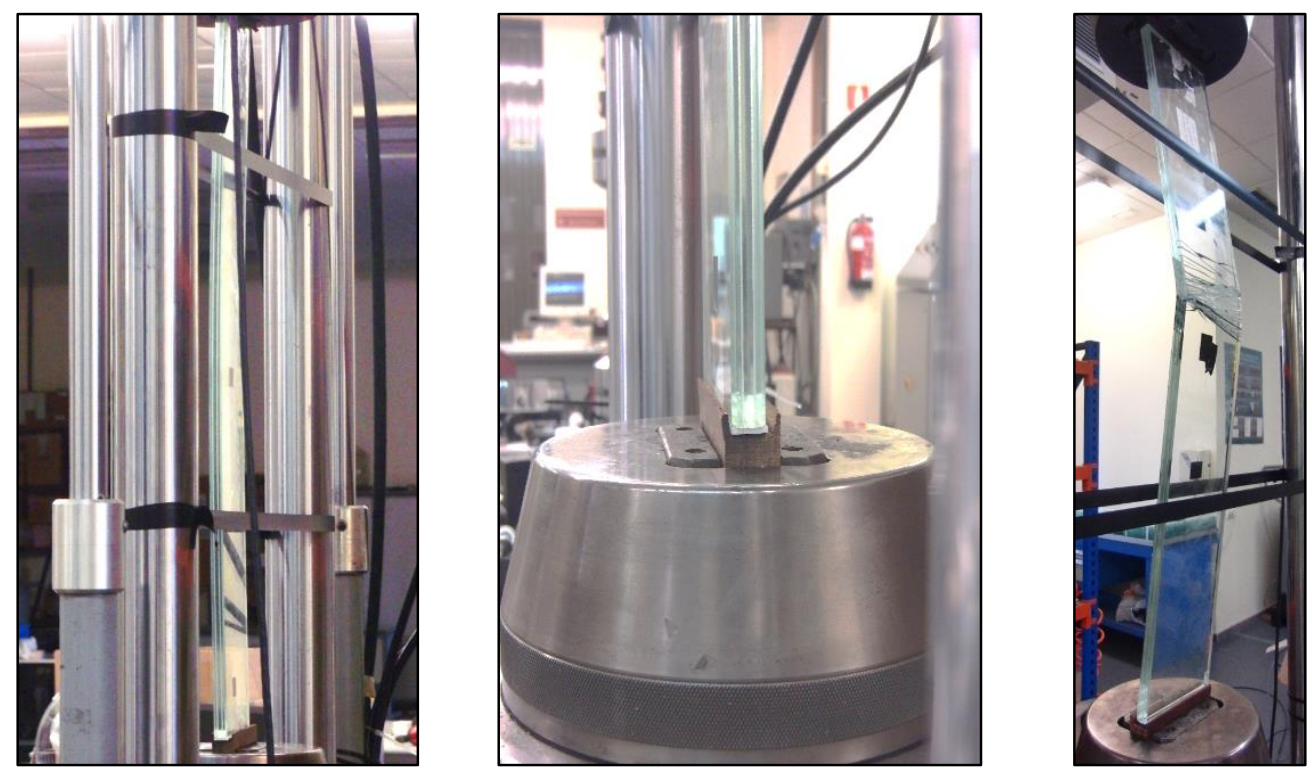

Figure 5. Buckling of a 3-glass layer simply supported beam $\left(\mathrm{L}=700 \mathrm{~mm}, H_{1}=H_{2}=\right.$ $H_{3}=4 \mathrm{~mm}, t_{1}=t_{2}=0.76 \mathrm{~mm}$ ). Details of the test setup and of the buckling failure of the beam.

In the analytical predictions, a Young modulus $E=70 \mathrm{GPa}$ and Poisson ratio $v=0.22$ were considered for the glass layers. With respect to the PVB, its mechanical properties were obtained in a previous work [17] using a DMA RSA3 (TA Instruments). For the PVB the WLF (Williams-Landel-Ferry) model [18] was used to take into account the temperature dependence whereas the master curve of the shear modulus $G(t)$ is represented by a generalized viscoelastic Maxwell model by means of a Prony series fit [19]:

$G_{t}(t)=G_{0}\left[1-\sum_{i=1}^{n_{t}} e_{i}\left(1-\exp \left(-\frac{t}{\tau_{i}}\right)\right)\right]$

where $G_{t}(t)$ is the shear relaxation modulus, $G_{0}$ the shear instantaneous modulus, $n_{t}$ the number of terms considered in the Prony series and $\left(e_{i}, \tau_{i}\right)$ are the Prony coefficients. 
The bulk modulus of PVB was assumed constant [20]. The material properties of PVB are presented in tables 1 and 2, respectively.

The critical load predicted with Eq. (6) is presented in figure 6 where it can be observed that, as expected, the critical load $P_{\text {crit }}$ decreases with time. The monolithic $\left(\mathrm{P}_{\text {crit }}^{0}\right)$ and layered $\left(\mathrm{P}_{\text {crit }}^{\infty}\right)$ limits as well as the maximum $\left(\mathrm{P}_{\text {crit }}^{\max }\right)$ and minimum $\left(\mathrm{P}_{\text {crit }}^{\min }\right)$ limits are also presented in the figure.

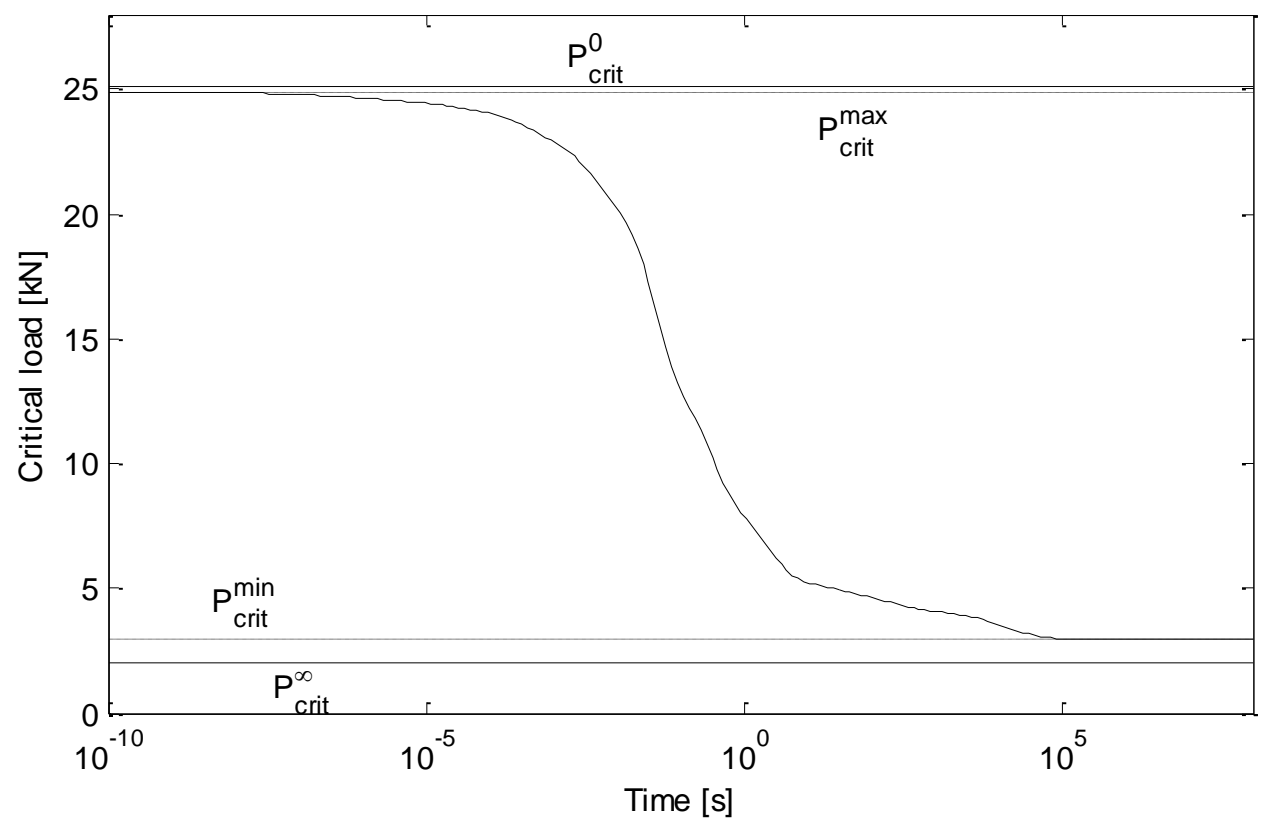

Figure 6. Predicted critical load for the 3 glass-layer laminated glass beam ( $\mathrm{L}=700 \mathrm{~mm}$, $\left.H_{1}=H_{2}=H_{3}=4 \mathrm{~mm}, t_{1}=t_{2}=0.76 \mathrm{~mm}\right)$ at $T=25^{\circ} \mathrm{C}$.

In figure 7 is presented the experimental axial load acting on the beam for the three axial displacement ratios used in the experiments together with the predicted critical loading. The experiments confirm that the critical loading decreases with time which is in good agreement with the relaxation trend of the predicted critical load. The experimental critical loadings together with those predicted with eq. (6) are presented in Table 3. 
Buckling is expected at the intersection of the buckling curve $P_{\text {crit }}(t, T)$ and the load curve $P(t)$. It can be observed in figure 7 that the experimental loadings $P(t)$ are slightly larger than the predicted critical loadings the larger error being less than $7 \%$ for $1 \mathrm{~mm} / \mathrm{min}$ axial displacement rate. This is in agreement with [9] where it is demonstrated that thanks to the delay in the stress relaxation, a beam for which the viscoelasticity of the interlayer is fully considered appears to be stiffer than when the response is evaluated by means of the quasi-elastic approximation. On the other hand, the ideal simply-supported boundary condition is difficult to reproduce experimentally and the experimental critical load is expected to be higher than that predicted with eq. (6).

The same was tested applying a constant compressive load of $4700 \mathrm{~N}$. The target load was reached with a constant loading rate of $100 \mathrm{~N} / \mathrm{s}$ (figure 8). As the axial load intersects the buckling critical load at short times, buckling was observed almost from the beginning of the test as it is confirmed by the displacement recorded with the laser sensor at the mid-point of the beam (figure 8).

As a final experiment, the beam was tested again up to breakage at a constant axial displacement rate of $1 \mathrm{~mm} / \mathrm{min}$. The experimental axial load and the bending deflection at the mid-point of the beam is shown in figure 9. It can be observed that the failure has not occurred at the mid-point of the beam (see figure 5) as it would be expected for a simply-supported beam, which indicates that the real boundary conditions were slightly different to those corresponding to a simply-supported beam. This fact (the beam is stiffer than the simply-supported one) also explains why the axial loadings needed for the buckling of the beam have been slightly higher than the predicted critical loading (see figure 7). 


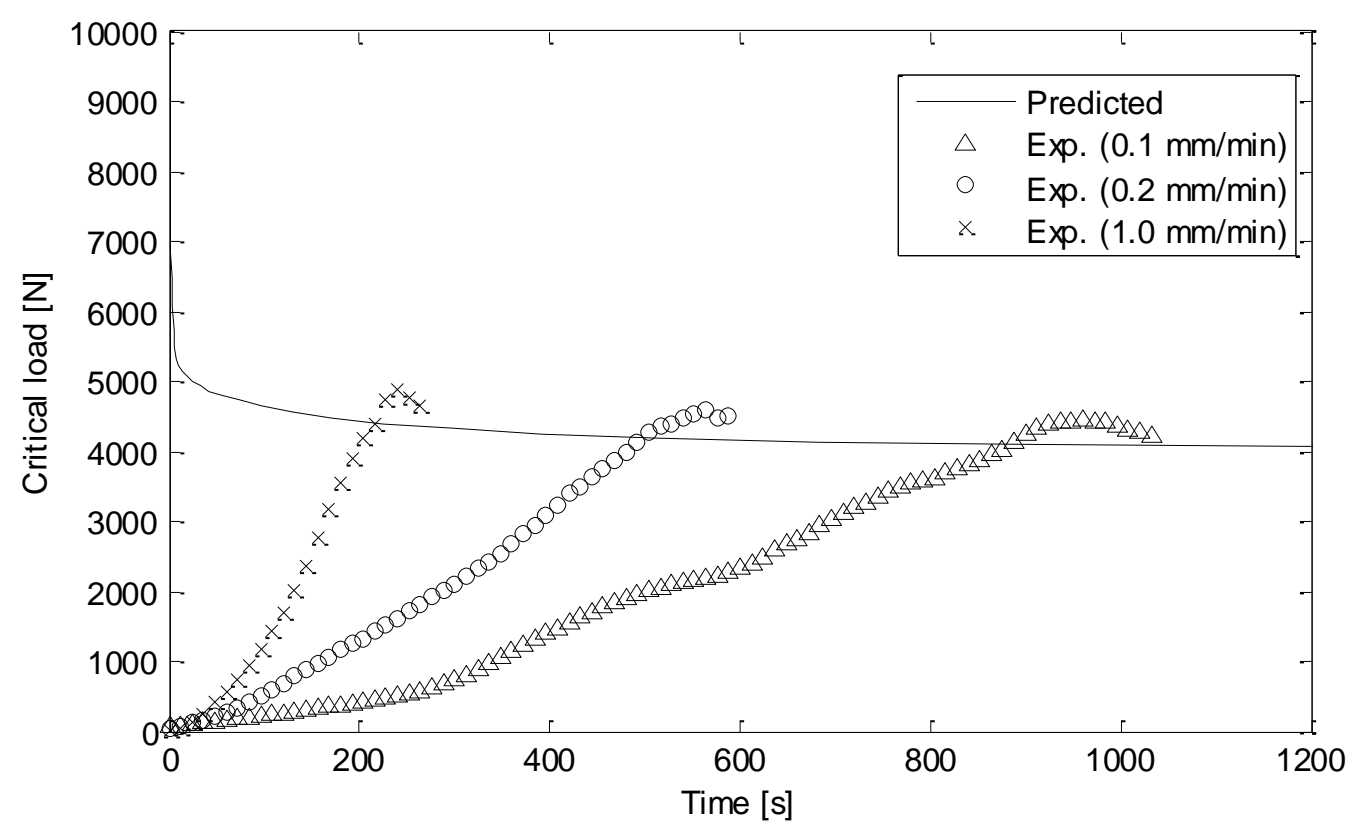

Figure 7. Buckling of a 3 glass-layer laminated glass beam ( $\mathrm{L}=700 \mathrm{~mm}, H_{1}=H_{2}=$ $H_{3}=4 \mathrm{~mm}, t_{1}=t_{2}=0.76 \mathrm{~mm}$ ) under simply-supported conditions. Temperature $T=$ $25^{\circ} \mathrm{C}$.

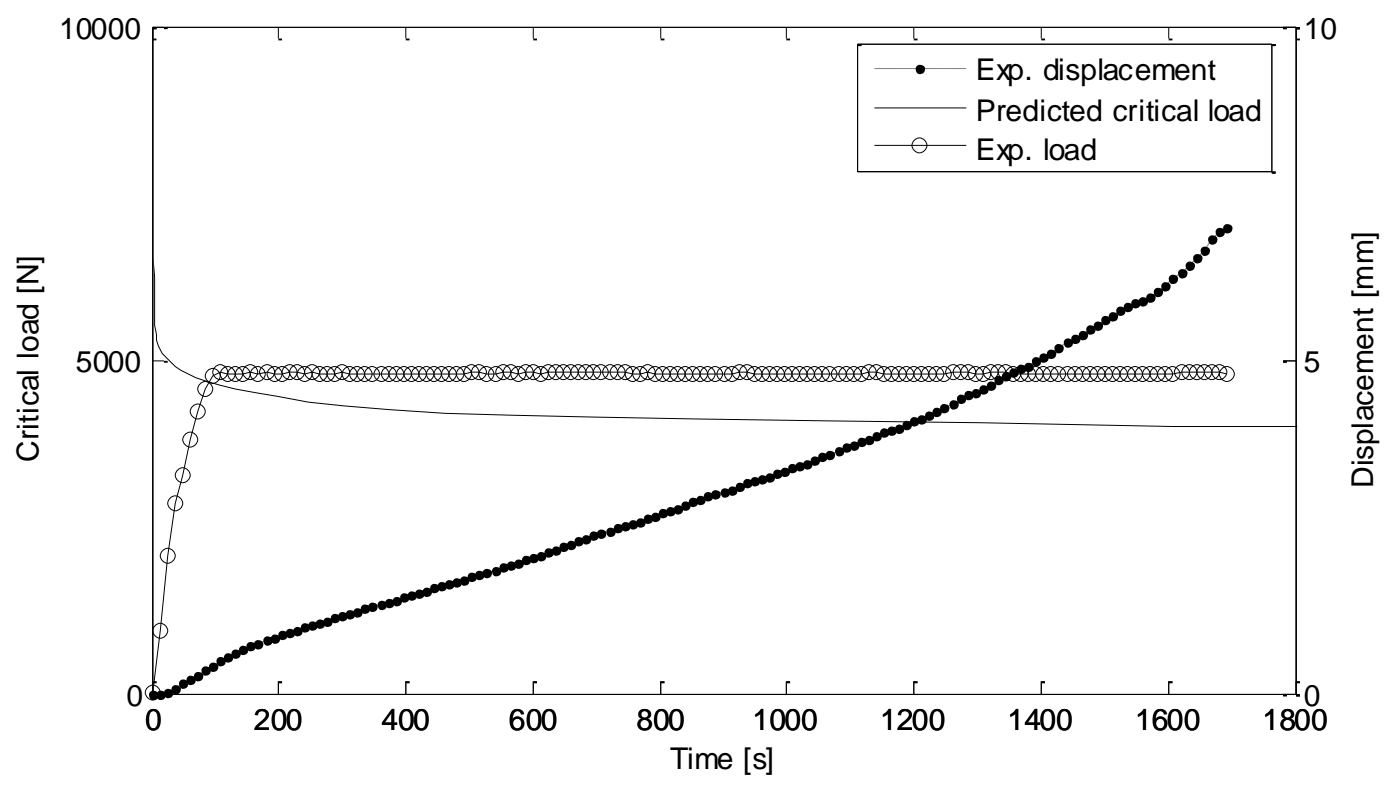

Figure 8. Buckling of a 3 glass-layer laminated glass beam $\left(\mathrm{L}=700 \mathrm{~mm}, H_{1}=H_{2}=\right.$ $H_{3}=4 \mathrm{~mm}, t_{1}=t_{2}=0.76 \mathrm{~mm}$ ) under simply-supported conditions (compressive constant force: $4700 \mathrm{~N}$ ). Temperature $T=25^{\circ} \mathrm{C}$. 


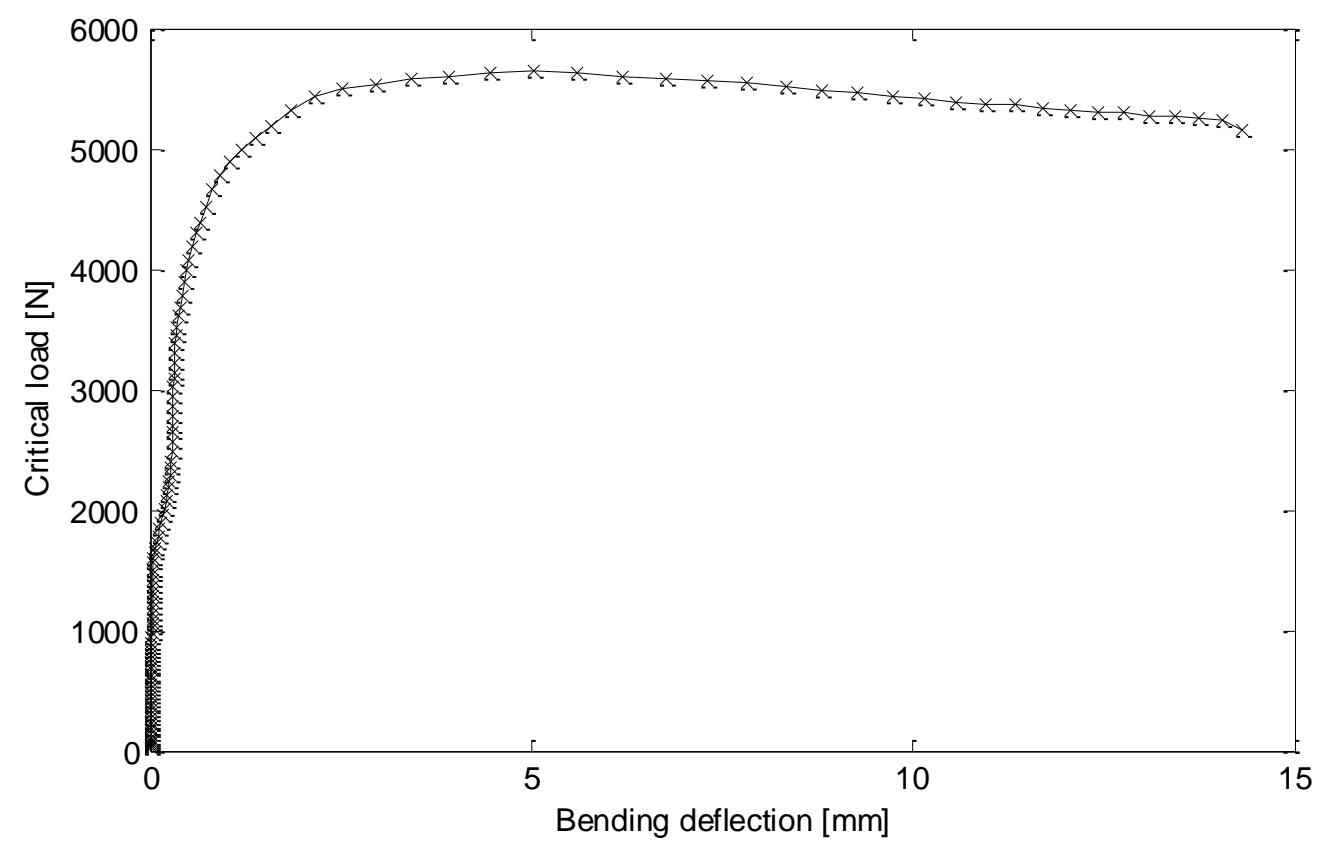

Figure 9. Buckling of a 3 glass-layer laminated glass beam up to breakage ( $\mathrm{L}=700 \mathrm{~mm}$, $H_{1}=H_{2}=H_{3}=4 \mathrm{~mm}, t_{1}=t_{2}=0.76 \mathrm{~mm}$ ) under simply-supported conditions (axial displacement rate $1 \mathrm{~mm} / \mathrm{min})$. Temperature $T=25^{\circ} \mathrm{C}$

In order to take into account the effect of the glass rupture stress dispersion, an additional specimen was tested at $20^{\circ} \mathrm{C}$ using the same axial displacement rates i.e. 0.1 $\mathrm{mm} / \mathrm{min}, 0.2 \mathrm{~mm} / \mathrm{min}$ and $1 \mathrm{~mm} / \mathrm{min}$, respectively. The relation between the axial force recorded by the machine and the bending deflection at the mid-span measured with a laser sensor is presented in figure 10 for the three cases. The experimental and the predicted critical loads are presented in figure 11 and in Table 3. 


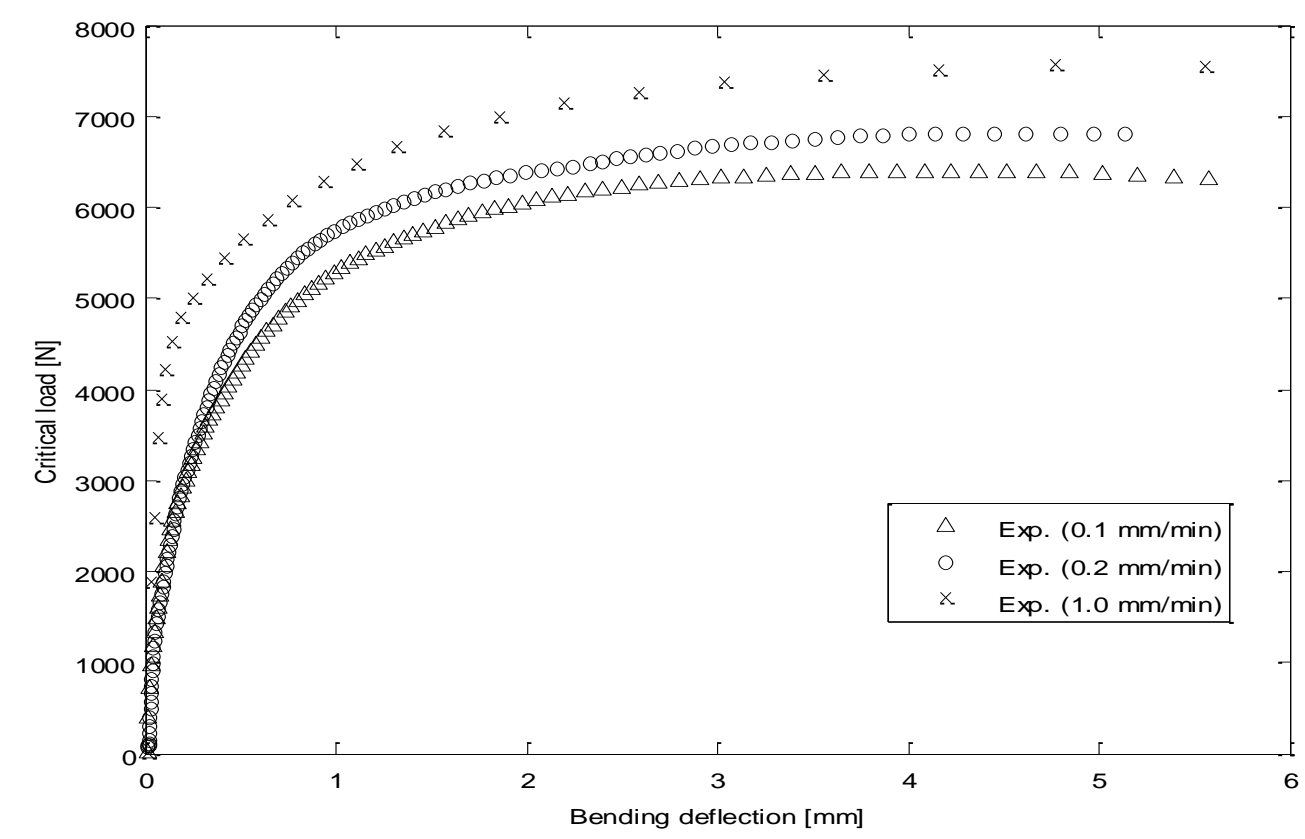

Figure 10. Critical load-bending displacement for the 3 glass-layer laminated glass beam $\left(\mathrm{L}=700 \mathrm{~mm}, H_{1}=H_{2}=H_{3}=4 \mathrm{~mm}, t_{1}=t_{2}=0.76 \mathrm{~mm}\right)$ at $T=20^{\circ} \mathrm{C}$.

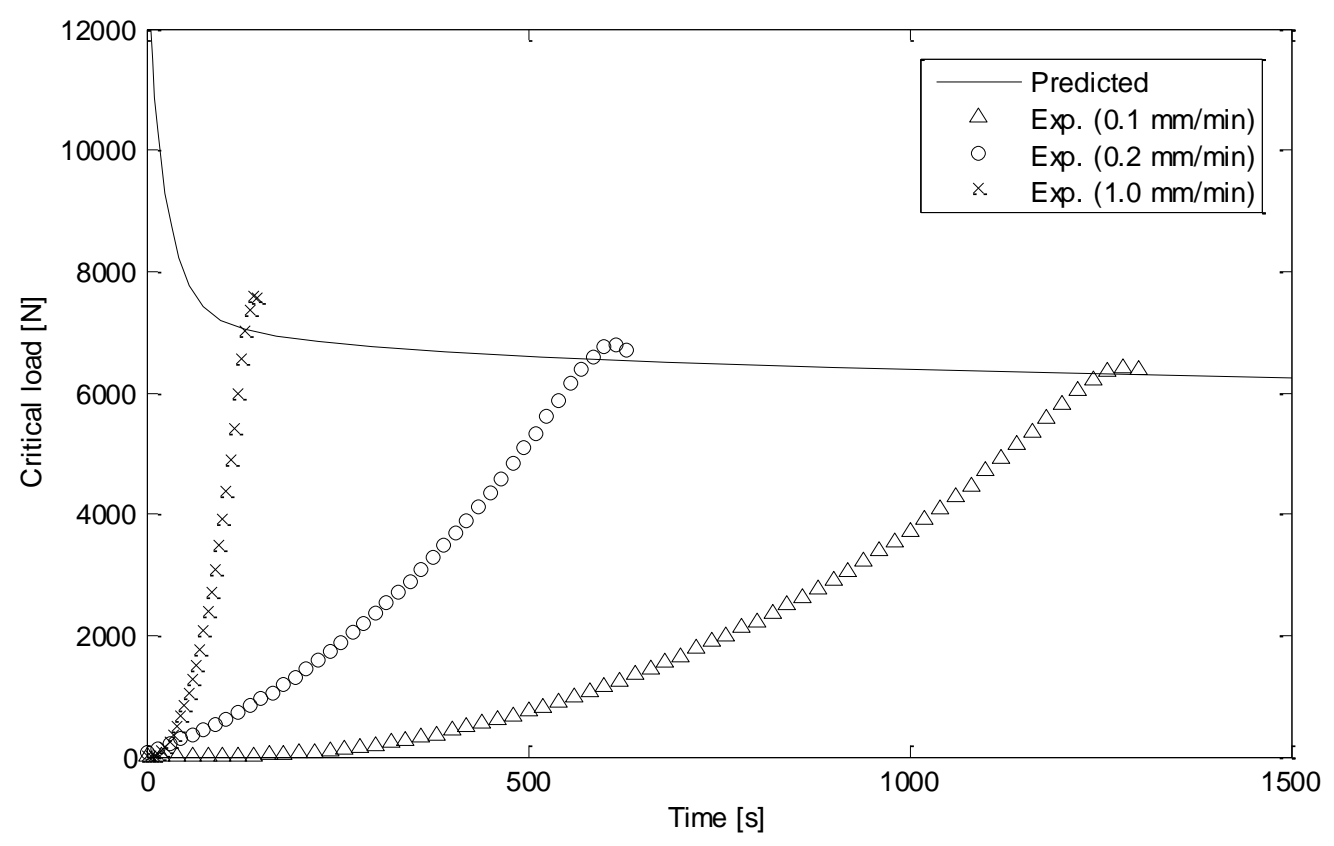

Figure 11. Buckling of a 3 glass-layer laminated glass beam ( $\mathrm{L}=700 \mathrm{~mm}, H_{1}=H_{2}=$ $\left.H_{3}=4 \mathrm{~mm}, t_{1}=t_{2}=0.76 \mathrm{~mm}\right)$ under simply-supported conditions. Temperature $T=$ $20^{\circ} \mathrm{C}$. 


\subsection{Numerical simulations}

Due to the brittle nature of the glass, fixed boundary conditions are difficult to reproduce experimentally. In order to validate the analytical equation (Eq. 6) proposed in this paper for the buckling of multilayered glass beams under any other boundary conditions, a finite element model was assembled in ABAQUS. Two classical boundary conditions were simulated for the beam: Pinned-Fixed $(\beta=0.7)$ and Fixed-Fixed $(\beta=$ 0.5). A linear elastic 3D model was assembled using quadratic hexaedric elements (reduced integration). The beam was meshed with five finite elements along the thickness (one element for each layer) and the same dimensions as those of the experimental beam were considered in the simulations ( $\mathrm{L}=700 \mathrm{~mm}, H_{1}=H_{2}=H_{3}=$ $4 \mathrm{~mm}, t_{1}=t_{2}=0.76 \mathrm{~mm}$ ). The finite element model of the beam as well as a detail of the mesh are shown in figure 12 .

The material properties considered in the simulations were the same as those used in the analytical predictions but modelling the PVB interlayer as a linear elastic material. The buckling load was calculated iteratively for each time $t=t_{i}$ considering for the interlayer a shear modulus $\left.G_{t}=G_{t}\left(t_{i}, T\right)\right)$ and a constant Poisson ratio $v_{t}=0.49$. A constant uniformly distributed axial loading with total magnitude $\mathrm{P}$ was applied on the top of the model. Then, a standard linear elastic analysis was carried out to obtain the stresses needed to form the geometric stiffness matrix $K_{G}$. Finally, an eigenvalue buckling analysis was run to predict the critical load $P_{\text {crit }}\left(t_{i}, T\right)$ corresponding to each time $t=t_{i}[12]$, which is obtained by: 


$$
P_{\text {crit }}\left(t_{i}, T\right)=\lambda_{1} \cdot P
$$

Where $\lambda_{1}$ is the first eigenvalue or multiplier of the reference load P. The eigenvalue problem was solved using the Lanczos method [21]. The same temperature $T=20^{\circ} \mathrm{C}$ was considered for both the numerical simulations and the analytical predictions.

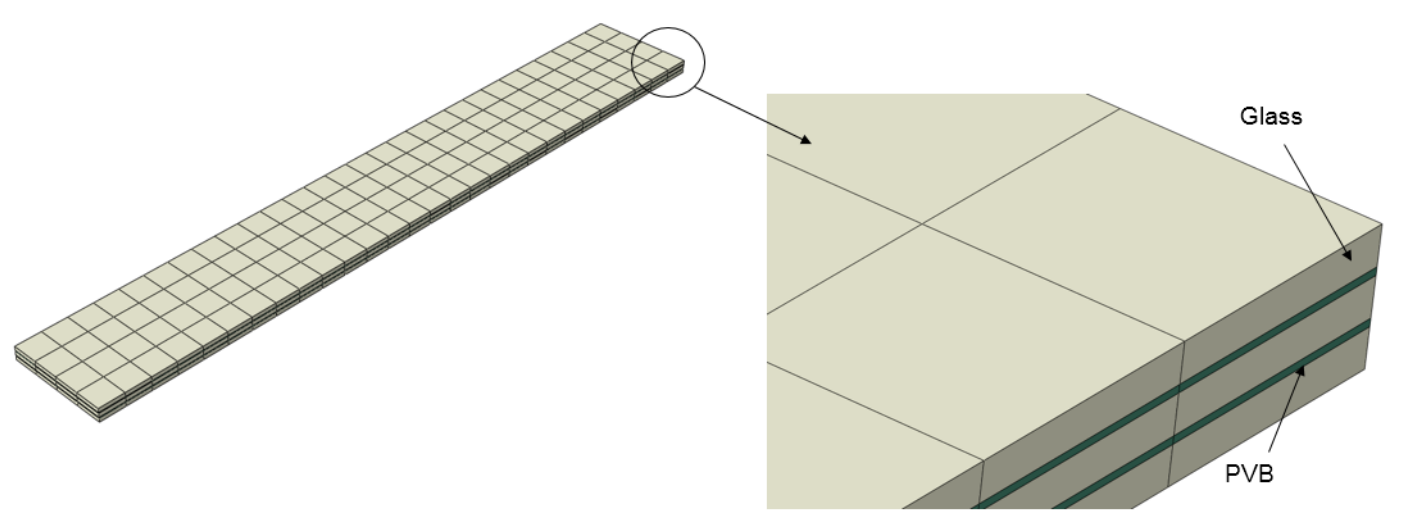

Figure 12. Finite element model and detail of the mesh used in the numerical simulations.

In figure 13 it is presented the critical load predicted with Eq. (6) using the buckling ratio $\beta=0.7$ (Pinned-Fixed), together with the critical load obtained with the FE model. From figure 13 it is inferred that a good correlation between the numerical simulations and the analytical predictions has been achieved, the error being less than $2 \%$. The corresponding buckling mode is shown in figure 15 . 


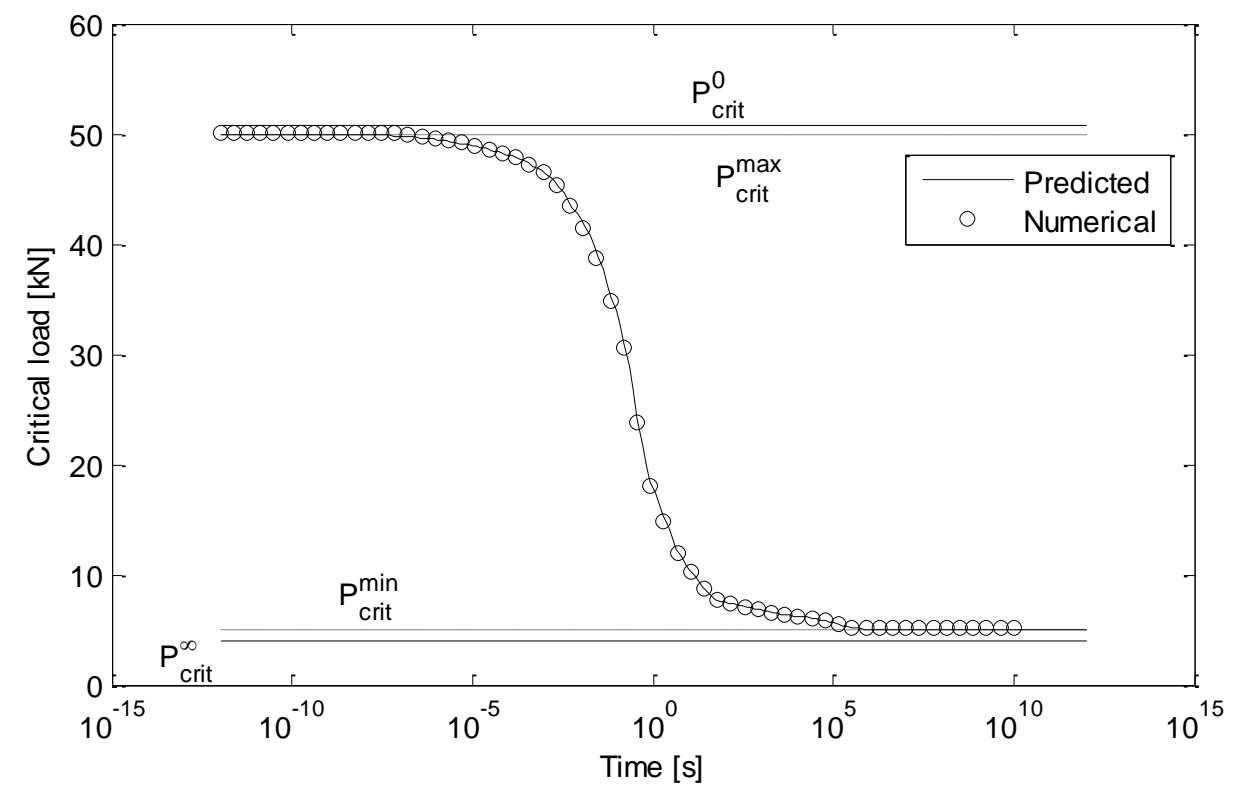

Figure 13. Analytical and numerical critical loadings predicted for the Fixed-Pinned boundary conditions.

Figure 14 shows the analytical and the numerical critical loads predicted for the beam under Fixed-Fixed configuration (buckling ratio $\beta=0.5$ ). The discrepancies between both models are less than 5\% and the corresponding buckling mode is also presented in figure 13 .

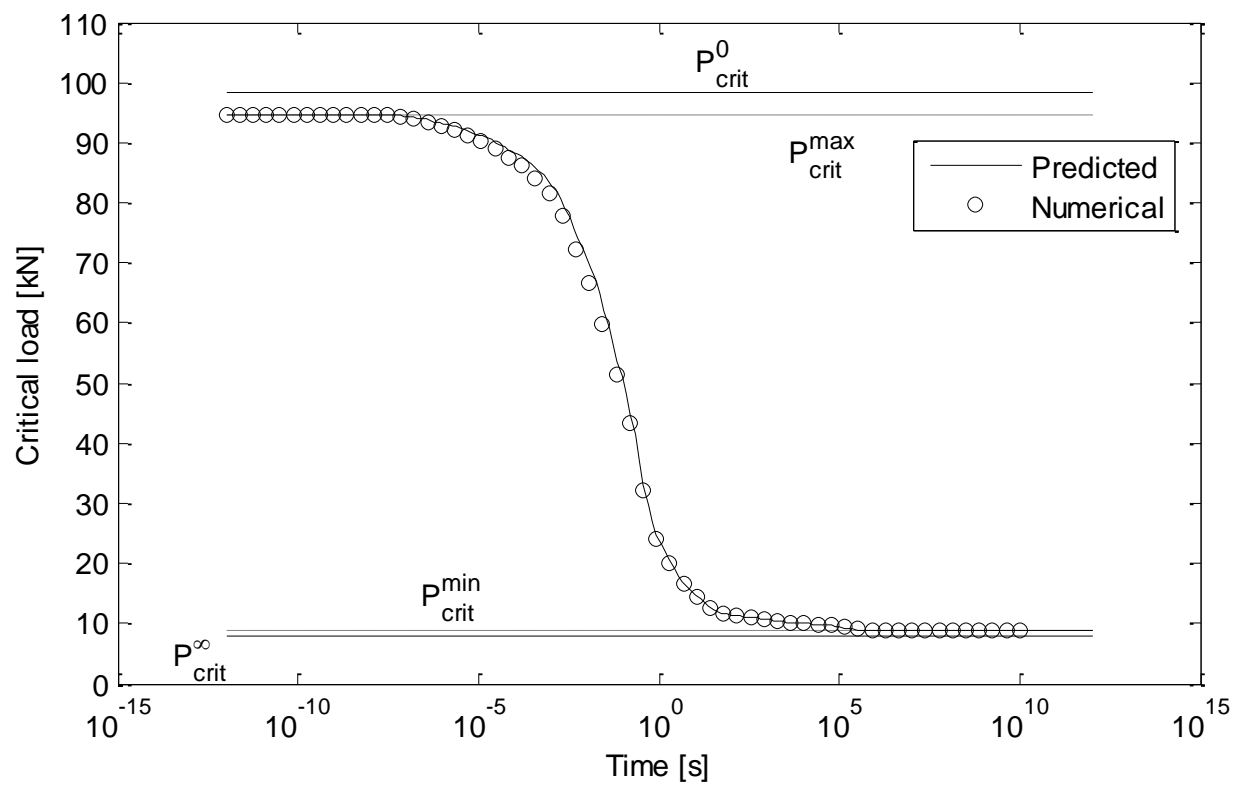


Figure 14. Analytical and numerical critical loadings predicted for the Fixed-Fixed boundary conditions.

The results shown in figures 13 to 14 prove that the proposed buckling equation (Eq. (6)) predicts with a good accuracy (errors less than a 5\%) the buckling load of a multilayered laminated glass beam with all the boundary conditions considered in this investigation.
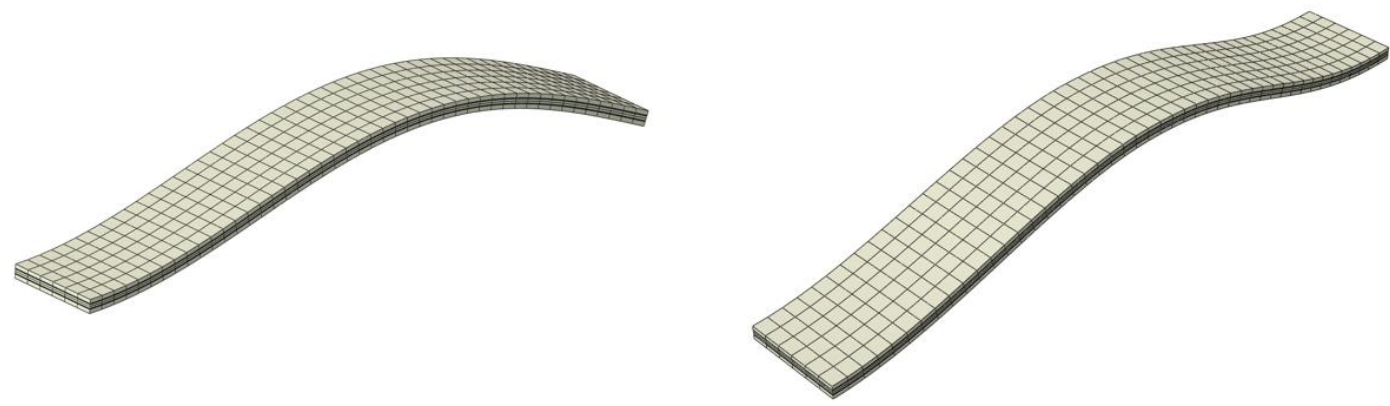

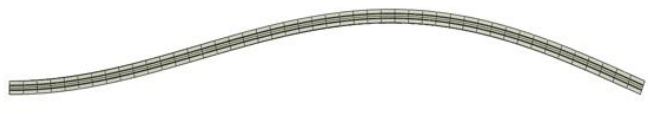

Pinned-Fixed

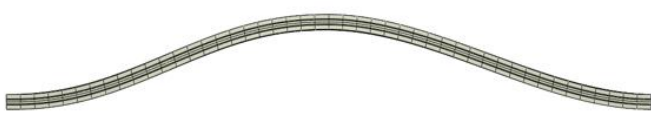

Fixed-Fixed

Figure 15. Numerical buckling modes of the beam for the two considered boundary conditions: Pinned-Fixed and Fixed-Fixed.

\section{CONCLUSIONS}

Structural stability is a design criterion to be considered in laminated glass elements subject to compressive loads. Due to the viscoelastic behavior of the interlayer materials, the critical load of a laminated glass beam decreases with time and, moreover, it is temperature dependent. This means that a safe procedure is needed in order to avoid failures due to buckling.

The layered critical load $P_{c r i t}^{\infty}$ given by the long-term limit of the interlayer shear modulus $G_{t}^{\infty}$, as suggested by several authors, can be used to obtain safe critical loads in laminated glass beams. However, depending on the geometry of the beam and on the 
boundary conditions, the minimum critical load $P_{\text {crit }}^{\text {min }}$ can be significantly higher than $P_{c r i t}^{\infty}$. Design with the limit $P_{c r i t}^{m i n}$ conducts to a thinner laminated glass beam and, moreover, it can be also considered a safe critical load.

In this paper, the classical Euler theory for buckling of isotropic monolithic beams have been extended to multilayered laminated glass beams using the effective stiffness concept. The buckling ratios of the classical Euler Theory for isotropic monolithic beams can also be used in multilayered laminated glass beams.

The accuracy provided by Eq. (6) has been validated by experimental compressive tests carried out on a simply supported beam $0.7 \mathrm{~m}$ long and $0.1 \mathrm{~m}$ wide and composed of three glass layers of thicknesses $H_{1}=H_{2}=H_{3}=4 \mathrm{~mm}$ and two PVB interlayers of thicknesses $t_{1}=t_{2}=0.76 \mathrm{~mm}$. The tests were performed at temperatures $T=$ $20{ }^{\circ} \mathrm{C}$ and $T=25^{\circ} C$. The error between the experimental critical load and those predicted with Eq. (6) are always less than $7 \%$.

In order to validate Eq. (6) for fixed boundary conditions (difficult to reproduce in monolithic and laminated glass panels), a finite element model was assembled in ABAQUS using quadratic hexaedric 3D elements and the critical load at temperature $T=20^{\circ} \mathrm{C}$ was calculated. Fixed-Pinned and Fixed-Fixed boundary conditions were considered in the simulations using the same geometrical data as those of the beam used in the experiments. The discrepancies between the numerical and the analytical results (Eq. (6)) are less than $5 \%$ which demonstrates that Eq. (6) predicts with a good accuracy the buckling load of a multilayered laminated glass beam with all the boundary conditions considered in the investigation.

Finally, it has also been demonstrated that the limits $P_{c r i t}^{\infty}$ and $P_{c r i t}^{\min }$ decrease as the number of layers increase, i.e. the maximum values of $P_{c r i t}^{\infty}$ and $P_{\text {crit }}^{\min }$ correspond to a laminated glass beam with two glass layers and one interlayer.

\section{ACKNOWLEDGEMENTS}

The financing support given by the Spanish Ministry of Economy and Competitiveness through the project BIA2014-53774-R is gratefully appreciated. 


\section{REFERENCES}

[1] Benninson, S., M.HX, Q. and Davies, P., High-performance laminated glass for structurally efficient glazing. Innovative Light-weight Structures and Sustainable Facades, Hong Kong, May, 2008.

[2] Wölfel, E., Nachgiebiger Verbund Eine Näherungslösung und deren Anwendungsmöglichkeiten, In: Stahlbau, 1987;6:173-180.

[3] Haldimann, M., Luible, A. and Overend, M. Structural Use of Glass. Structural Engineering Documents (10). IABSE, 2008.

[4] Calderone, I., Davies, P.S., and Benninson, S.J., Effective Laminate Thickness for the Design of Laminated Glass. In: Glass Processing Days, Tampere, Finland, 2009.

[5] Galuppi, L., and Royer-Carfagni, G.F., Laminated beams with viscoelastic interlayer, International Journal of Solids and Structures. 2012;49:2637-2645.

[6] Galuppi, L., and Royer-Carfagni, G.F., Effective Thickness of Laminated Glass Beams: New Expression via a Variational Approach, Journal of Structural Engineering, 2012;38:53-67.

[7] López-Aenlle, M., Pelayo, Dynamic effective thickness in laminated-glass beams and plates. Composites Part B-Engineering. 2014; 67:332-347.

[8] Blaauwendraad, J., Buckling of laminated glass columns. HERON, 2007;52(1/2):147-218.

[9] Galuppi, L., and Royer-Carfagni, G.F., Buckling of three-layered composite beams with viscoelastic interaction. Composite Structures, 2014;107:512-521.

[10] Feldmann, M., Kasper, R. et al. Guidance for European Structural Desing of Glass Components. JCR Scientific and Policy Report, doi: 10.2788/5523, 2014.

[11] Foraboschi P. Buckling of a laminated glass column under test. Structural Engineering, 2009;87(1). 
[12] López-Aenlle, M. Pelayo, F., Ismael, G., García Prieto, M.A., Martín Rodríguez, A., Fernández-Canteli, A. Buckling of laminated-glass beams using the effective thickness concept. Composites Structures, 2016:137:44-55.

[13] Timoshenko, S.P., Gere, J.M. Theory of elastic stability. McGraw Hill, London, 1963.

[14] Chajes, A., Principles of Structural Stability Theory (Civil engineering and engineering mechanics series). Prentice Hall, 1974.

[15] Galuppi, L. and Royer-Carfagni, G.F. Enhanced Effective Thickness of MultiLayered Laminated Glass. Composites Part B-Engineering. 2014;64:202-213.

[16] Norville, H.S., King, K.W., and Swoord, J.L., Behavior and strength of laminated glass, Journal of Engineering Mechanics. 1998;124(1):46-53.

[17] López-Aenlle, M., Pelayo, F., Frequency Response of Laminated Glass Elements: Analytical Modelling and Effective Thickness, Applied Mechanics Reviews, 2013;65(2), 020802 (13 pages).

[18] Williams, M.L., Landel, R.F., and Ferry, J., The Temperature Dependence of Relaxation Mechanisms in Amorphous Polymers and Other Glass-forming Liquids, Journal of American Chemical Society, 1955;77:3701-3707.

[19] T. Chen. Determining a Prony Series for a Viscoelastic Material from Time Varying Strain Data. NASA/TM-2000-210123. ARL-TR-2206. 2000.

[20] Benninson, S., Jagota, A., and Smith, C., Fracture of glass/pvb laminates in biaxial flexure. Journal of the American Ceramic Society, 1999;82:1761-1770.

[21] Zienkiewicz, O.C., Taylor, R.L. and Zhu, J.Z. The finite element method, its basis $\&$ fundamentals. $6^{\text {th }}$ Edition. Elsevier. 2005. 
Figure captions:

Figure 1. Section of laminated glass beams (a) 2 glass layers (b) 3 glass layers and (c) $\mathrm{N}$ glass layers of equal thickness.

Figure 2. Critical load of a simple supported laminated glass beam at different temperatures.

Figure 3. Comparison of the critical load for same total thickness between a 3 layered and 2 layered (sandwich) laminated glass beams.

Figure 4. Influence of the number of layers on the minimum critical load $\mathrm{P}_{\text {crit }}^{\min }$.

Figure 5. Buckling of a 3-glass layer simply supported beam ( $\mathrm{L}=700 \mathrm{~mm}, H_{1}=H_{2}=$ $H_{3}=4 \mathrm{~mm}, t_{1}=t_{2}=0.76 \mathrm{~mm}$ ). Details of the test setup and of the buckling failure of the beam.

Figure 6. Predicted critical load for the 3 glass-layer laminated glass beam ( $\mathrm{L}=700 \mathrm{~mm}$, $\left.H_{1}=H_{2}=H_{3}=4 \mathrm{~mm}, t_{1}=t_{2}=0.76 \mathrm{~mm}\right)$ at $T=25^{\circ} \mathrm{C}$.

Figure 7. Buckling of a 3 glass-layer laminated glass beam $\left(\mathrm{L}=700 \mathrm{~mm}, H_{1}=H_{2}=\right.$ $H_{3}=4 \mathrm{~mm}, t_{1}=t_{2}=0.76 \mathrm{~mm}$ ) under simply-supported conditions.

Figure 8. Buckling of a 3 glass-layer laminated glass beam ( $\mathrm{L}=700 \mathrm{~mm}, H_{1}=H_{2}=$ $H_{3}=4 \mathrm{~mm}, t_{1}=t_{2}=0.76 \mathrm{~mm}$ ) under simply-supported conditions (compressive constant force: $4700 \mathrm{~N}$ ).

Figure 9. Buckling of a 3 glass-layer laminated glass beam up to breakage ( $\mathrm{L}=700 \mathrm{~mm}$, $H_{1}=H_{2}=H_{3}=4 \mathrm{~mm}, t_{1}=t_{2}=0.76 \mathrm{~mm}$ ) under simply-supported conditions (axial displacement rate $1 \mathrm{~mm} / \mathrm{min})$.

Figure 10. Critical load-bending displacement for the 3 glass-layer laminated glass beam $\left(\mathrm{L}=700 \mathrm{~mm}, H_{1}=H_{2}=H_{3}=4 \mathrm{~mm}, t_{1}=t_{2}=0.76 \mathrm{~mm}\right)$ at $T=20^{\circ} \mathrm{C}$. 
Figure 11. Buckling of a 3 glass-layer laminated glass beam ( $\mathrm{L}=700 \mathrm{~mm}, H_{1}=H_{2}=$ $H_{3}=4 \mathrm{~mm}, t_{1}=t_{2}=0.76 \mathrm{~mm}$ ) under simply-supported conditions. Temperature $T=$ $20^{\circ} \mathrm{C}$.

Figure 12. Finite element model and detail of the mesh used in the numerical simulations.

Figure 13. Analytical and numerical critical loadings predicted for the Fixed-Pinned boundary conditions.

Figure 14. Analytical and numerical critical loadings predicted for the Fixed-Fixed boundary conditions.

Figure 15. Numerical buckling modes of the beam for the two considered boundary conditions: Pinned-Fixed and Fixed-Fixed. 
Table 1 Material properties for glass and PVB

Glass PVB

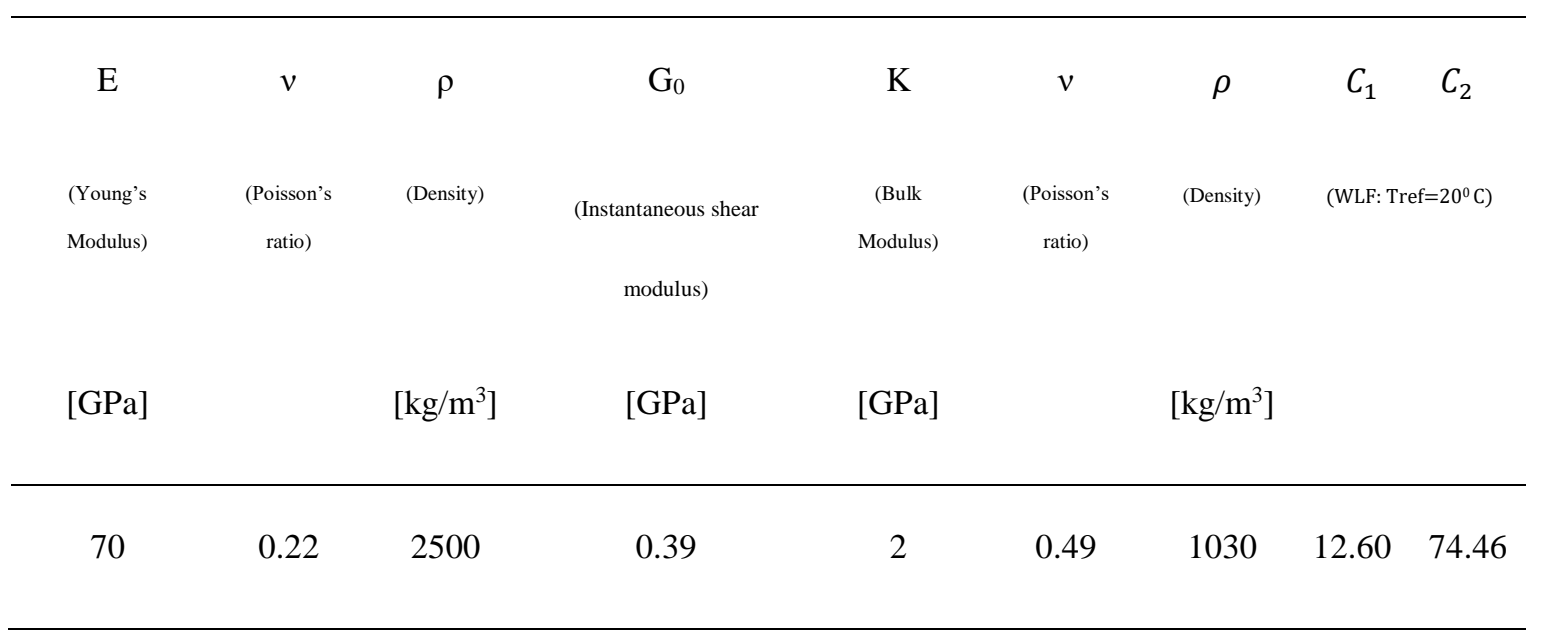


Table 2 Prony series coefficients for PVB

\begin{tabular}{cc}
$\tau_{i}[\mathrm{~s}]$ & $e_{i}$ \\
\hline $2.36600000000000 \mathrm{E}-07$ & $2.342151953 \mathrm{E}-01$ \\
$2.26430000000000 \mathrm{E}-06$ & $2.137793134 \mathrm{E}-01$ \\
$2.16668000000000 \mathrm{E}-05$ & $1.745500419 \mathrm{E}-01$ \\
$2.07327300000000 \mathrm{E}-04$ & $1.195345045 \mathrm{E}-01$ \\
$1.98389580000000 \mathrm{E}-03$ & $1.362133454 \mathrm{E}-01$ \\
$1.89837195000000 \mathrm{E}-02$ & $6.840656310 \mathrm{E}-02$ \\
$1.81653498300000 \mathrm{E}-01$ & $4.143944180 \mathrm{E}-02$ \\
$1.73822593210000 \mathrm{E}+00$ & $7.251952800 \mathrm{E}-03$ \\
$1.66329270788000 \mathrm{E}+01$ & $2.825459600 \mathrm{E}-03$ \\
$1.59158978189400 \mathrm{E}+02$ & $2.712854000 \mathrm{E}-04$ \\
$1.52297789909670 \mathrm{E}+03$ & $4.293523000 \mathrm{E}-04$ \\
$1.45732380763177 \mathrm{E}+04$ & $9.804730000 \mathrm{E}-05$ \\
$1.39449999999999 \mathrm{E}+05$ & $5.274937000 \mathrm{E}-04$ \\
\hline
\end{tabular}


Table 3. Experimental and analytical critical loadings for the 3 glass-layer laminated glass beam $\left(\mathrm{L}=700 \mathrm{~mm}, H_{1}=H_{2}=H_{3}=4 \mathrm{~mm}, t_{1}=t_{2}=0.76 \mathrm{~mm}\right)$.

\begin{tabular}{|c|c|c|c|c|c|}
\hline \multicolumn{6}{|c|}{ Experimental } \\
\hline $\begin{array}{c}\mathrm{T}^{\mathrm{a}} \\
{\left[{ }^{\circ} \mathrm{C}\right]}\end{array}$ & $\begin{array}{c}\text { Axial } \\
\text { displacement } \\
\text { rate } \\
{[\mathrm{mm} / \mathrm{min}]}\end{array}$ & $\begin{array}{c}t_{\text {crit }} \\
{[s]}\end{array}$ & $\begin{array}{c}P_{\text {crit }} \\
{[\mathrm{N}]}\end{array}$ & $\begin{array}{c}\text { Analytical } \\
P_{\text {crit }} \text { at } t_{\text {crit }} \\
{[N]}\end{array}$ & $\begin{array}{c}\text { Erron } \\
{[\%]}\end{array}$ \\
\hline \multirow{3}{*}{$25^{\circ} \mathrm{C}$} & 0.1 & 960 & 4370 & 4095 & 6.29 \\
\hline & 0.2 & 564 & 4468 & 4185 & 6.33 \\
\hline & 1 & 240 & 4793 & 4465 & 6.84 \\
\hline \multirow{3}{*}{$20^{\circ} \mathrm{C}$} & 0.1 & 1280 & 6421 & 6310 & 1.78 \\
\hline & 0.2 & 615 & 6802 & 6550 & 3.70 \\
\hline & 1 & 140 & 7585 & 7100 & 6.40 \\
\hline
\end{tabular}

